AMRP

\title{
The Economic Impact of Supporting Working Family Caregivers
}

Helping caregivers age 50-plus stay in the workforce could add $\$ 1.7$ trillion to U.S. GDP in 2030

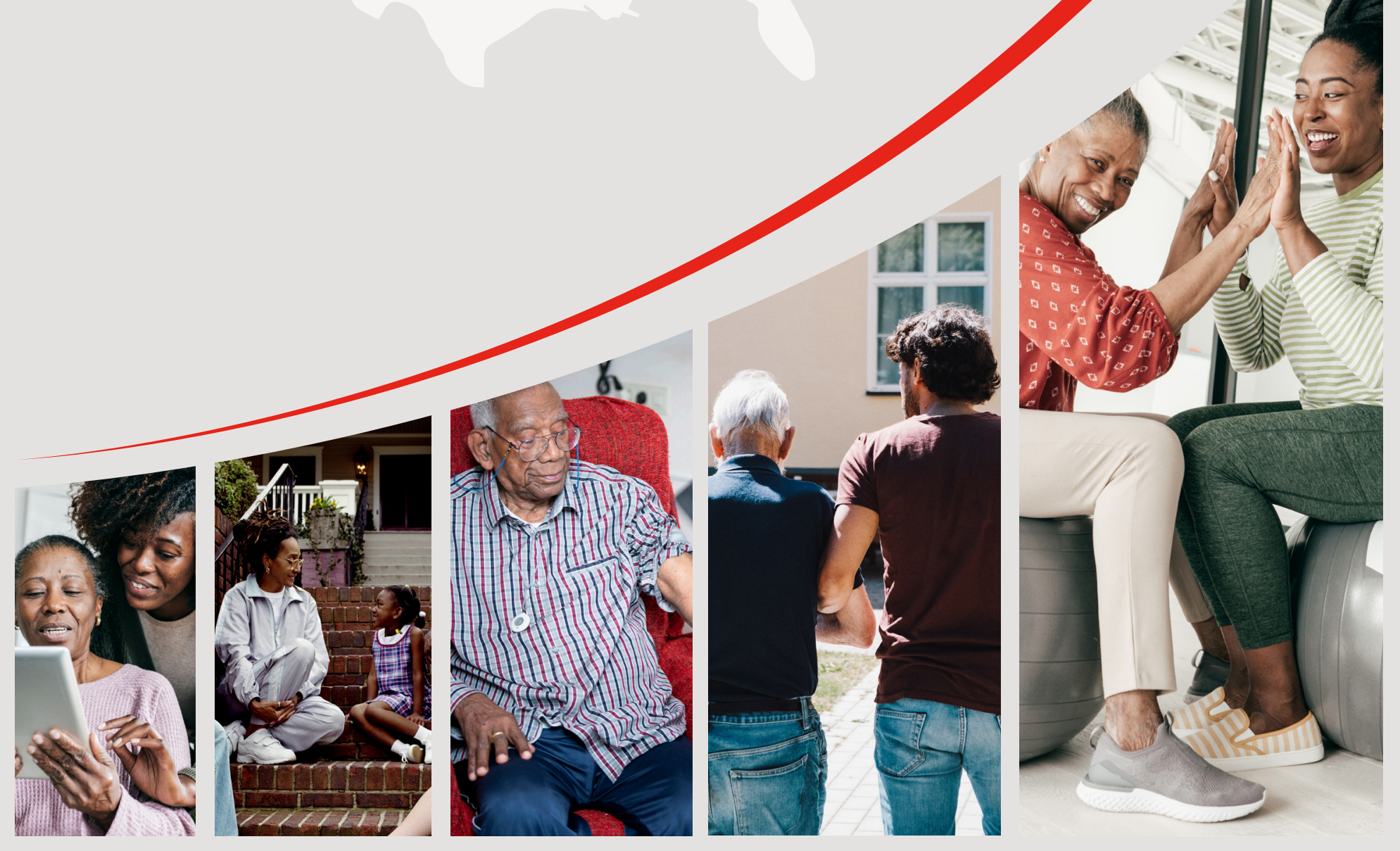




\section{Contents}

Executive summary $\quad 2$

Key insights $\quad 5$

Introduction 6

$\begin{array}{ll}\text { Family caregiving and the labor force } & 7\end{array}$

The effects of family caregiving across demographic groups 10

Measuring the economic impact of supporting 12 employed family caregivers

Capturing the benefits of better support for family caregivers 18

Final thoughts: Supporting working family caregivers 21

is an investment with a strong return

Appendix 1: Notes on the methodology 22

Appendix 2: Charts and tables 25 


\section{Executive summary}

Today, almost 48 million

Americans are family caregivers

providing care to a family

member or friend age 18 or

older. ${ }^{1}$ Caregivers on the whole

are becoming as diverse as

the American population.

Four in ten caregivers are from multicultural communities. About 40 percent of family caregivers are men. Eight percent self-identify as lesbian, gay, bisexual, and/or transgender. While their average age is 49.4 years old, the experience of being a family caregiver cuts across all generations, including Boomer, Gen-X, Gen-Z, Millennial, and Silent. For example, nearly one in four (24 percent) family caregivers is a Millennial. One in ten family caregivers is a student enrolled in college or other courses, while 9 percent have served on active duty in the U.S. Armed Forces. ${ }^{2}$

The need for caregiving is growing, driven in part by the aging populationparticularly the expansion of the age 80-plus cohort, which is the age group with the highest need for long-term services and supports (LTSS). As of 2020, 12.9 million people over age 80 live in the U.S., a number that is projected to more than double by 2040, when those 80-plus will comprise 7.4 percent of the population. ${ }^{3}$ Already today, caring for this growing pool of older Americans (as well as other adults of all ages) is a massive army of unpaid family caregivers, ${ }^{4}$ many of whom are over age 50 themselves. ${ }^{5}$

The role of family caregiving represents a crucial thread in our social fabric. Yet the thread is frayed, particularly with respect to those who work. More than 60 percent of family caregivers endure some type of work-related difficulty in order to tend to their families or friends. ${ }^{6}$ One in five family caregivers reports feeling isolated. ${ }^{7}$ Half of family caregivers who are working do not have access to paid family leave and nearly as many are paying bills late, skipping mortgage payments, or going into debt. ${ }^{8}$ The COVID-19 pandemic only compounds the mental, physical, and financial challenges of performing in this role. It also makes working caregivers even more vulnerable to layoffs and furloughs.?

This reality has significant implications for the economy. Family caregivers of all ages are major contributors to businesses and the overall economy; meanwhile, the contribution of the many caregivers age 50-plus are particularly notable, as they are often in the prime of their careers and possess valuable skills and experience. And yet many forces work against them. Inadequate caregiver supports, ${ }^{10}$ in both workplace and government policies

\section{KEY TERMS}

Family caregivers: This study focuses on family caregivers age 50 and older who care for an adult (either family or friend) age 18 and older. Caregiving is defined as doing a range of activities to help an older person or other adult with a chronic, disabling, or serious health condition. Such assistance can include help with personal care and daily activities such as bathing, dressing, paying bills, handling insurance claims, preparing meals, or providing transportation; carrying out medical or nursing tasks; locating, arranging, and coordinating services and supports; communicating with health and social service providers; and implementing care plans.

\section{Working family caregivers: This includes anyone} who is employed (either full-time or part-time) in an organization or business while also providing care for an older relative or friend, or an adult family member or friend with a disability.

Long-Term Services and Supports (LTSS): LTSS consist of a broad range of day-to-day help needed by people with long-term conditions, disabilities, or frailty. This can include personal care (bathing, dressing, toileting); complex care (medications, wound care); help with housekeeping, transportation, paying bills, and meals; and other ongoing social services. LTSS may be provided in the home, in assisted living and other supportive housing settings, in nursing facilities, and in integrated settings such as those that provide both health care and supportive services. LTSS also include supportive services provided to family members and other unpaid caregivers.

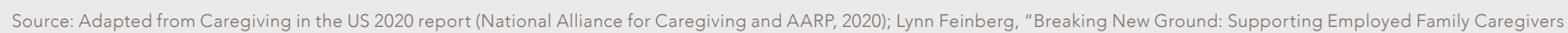
with Workplace Leave Policies, (Washington, DC: AARP Public Policy Institute, 2018); and AARP Public Policy Institute, "Long-Term Services and Supports State Scorecard 2020 Edition" (Washington, DC: AARP Public Policy Institute, 2020).

1. AARP and National Alliance for Caregiving. "Caregiving in the United States 2020." Washington, DC: AARP. May 2020. https://doi.org/10.26419/ppi.00103.001.

2. AARP and National Alliance for Caregiving. "Caregiving in the United States 2020." Washington, DC: AARP. May 2020. https://doi.org/10.26419/ppi.00103.001.

3. Data from Regional Economic Models, Inc. (REMI).

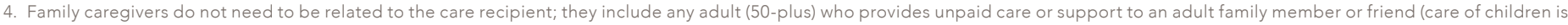
not included)

5. AARP and National Alliance for Caregiving. "Caregiving in the United States 2020." Washington, DC: AARP. May 2020. https://doi.org/10.26419/ppi.00103.001.

6. See Figure 4.

7. AARP and National Alliance for Caregiving. "Caregiving in the United States 2020." Washington, DC: AARP. May 2020. https://doi.org/10.26419/ppi.00103.001.

8. AARP and National Alliance for Caregiving. "Caregiving in the United States 2020." Washington, DC: AARP. May 2020. https://doi.org/10.26419/ppi.00103.001.

9. AARP and S\&P Global, "Something's Gotta Give," 2020. https://www.spglobal.com/en/research-insights/featured/somethings-gotta-give.

10. This study defines caregiver support as any financial or non-financial assistance that helps unpaid family caregivers better undertake their care duties and successfully balance their employment obligations. This includes supports such as flexible work options, government programs, and trainings and information. See figure 17 for a sample list of common caregiver support resources. 
and practices, affect family caregivers' workforce participation and, in some cases, drive them out of the labor force altogether, resulting in lost opportunities for economic growth. Policies that support working caregivers, therefore, can benefit both companies and the economy by enhancing productivity, all while enabling them to keep up with their caregiving responsibilities.

In fact, their value to the economy and society is more important than ever. With the U.S. now facing unprecedented economic and public health challenges due to the COVID-19 pandemic, the 50-plus population will play a critical role in the nation's recovery-economic, social, health, and otherwise. This group already drives economic growth through labor force participation and spending, but their contribution as family caregivers has an underappreciated impact on our society-an impact that can even be measured in dollars. In 2018, the total estimated economic value of family caregiving was approximately $\$ 470$ billion. ${ }^{11}$ People age 50 -plus in the U.S. spent an average of 164 hours per year caring for adults, equivalent to over $\$ 260$ billion in the total value of caregiving. ${ }^{12}$ By better engaging and supporting these caregiving efforts, the U.S. could both maintain and support this invaluable contribution and enable greater workforce participation among family caregivers of all ages, especially those age 50-plus.

While caregiving cuts across all generations, this AARP study ${ }^{13}$ explores the potential economic benefits that can be captured if employers and governments provide better support for working family caregivers age 50 plus, enabling them to remain more active participants in the labor force. The prolonged economic downturn makes it especially important for working family caregivers-particularly workers age 50-plus who are in their peak earning years - to stay in the workforce. Greater recognition and investments in caregiving support for this population can benefit caregivers of all ages and build a stronger economy while creating a more inclusive and caring society.

11. AARP's "Valuing the Invaluable: 2019 Update." https://www.aarp.org/content/dam/aarp/ppi/2019/11/valuing-the-invaluable-2019-update-charting-a-path-forward.doi.10.264192Fppi.00082.001.pdf.

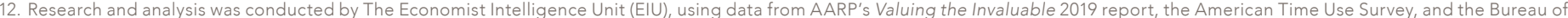
Labor Statistics.

13. Research and analysis was conducted by The Economist Intelligence Unit (EIU) 


\section{Key insights}

If family caregivers age 50-plus have access to support in the workplace, U.S. Gross Domestic Product (GDP) could grow by an additional \$1.7 trillion (5.5 percent) in 2030_a figure equivalent to the state of New York's total economy and larger than Florida's-and by $\$ 4.1$ trillion (6.6 percent) in 2050, an increase equal to the current combined economies of California and Florida.

\section{\$1.7 trillion in 2030}
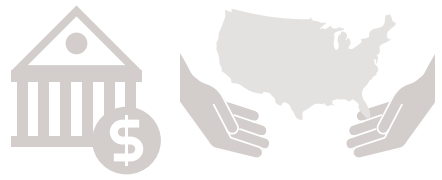

\section{Women suffer more adverse}

consequences than men as a result of family caregiving. Family caregivers dropping out of the workforce represent the largest potential cost to the economy. This effect is especially pronounced for women-particularly those with low incomes-who experience labor force dropout and early retirement at a rate more than three times more than men.

Jobs, wages, and salaries would see steady growth from increased caregiving support in the workplace. Providing support to 50-plus family caregivers and allowing them to remain active participants in the labor force will support 10.7 million jobs and a 5.6 percent increase in wages and salaries across the U.S. in 2030. In 2050, supporting caregivers age 50-plus in the workplace will support 13.1 million jobs and result in a 6.7 percent increase in wages and salaries.

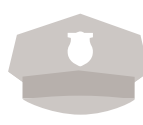

\section{7 million 2030}

13.1 million 2050

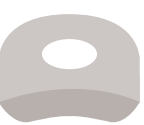

Increasing caregiving support for 50-plus family caregivers in the workplace will cause consumer spending to grow across industries. Spending on technology products, financial services and insurance, transportation services, and motor vehicles will see the biggest gains, with increases of 7 percent in 2030 and of 9 percent in 2050 across these combined categories.

p
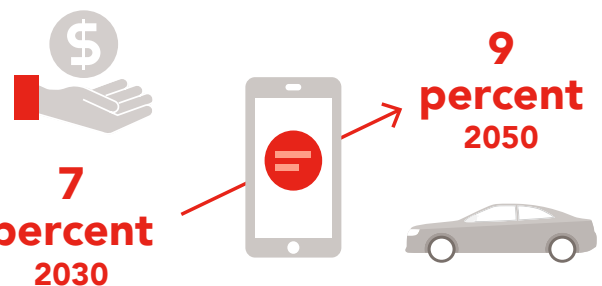

Some family caregivers experience being penalized or discriminated against due to their caregiving responsibilities. While this cuts across all racial/ethnic groups, African Americans were more likely to report a higher occurrence of penalization or discrimination at work due to their caregiving obligations.

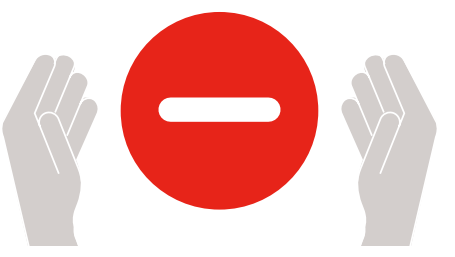

Key supports from governments and employers would help caregivers of all ages remain engaged in the workforce. Research shows that more than 75 percent of family caregivers age 50-plus who retired early because of family caregiving responsibilities would have remained in the workforce longer if they had access to financial supports (such as paid family/sick leave, FMLA eligibility, respite services, long-term care insurance, and care subsidies) or nonfinancial supports (such as employee assistance programs, flexible hours/shifts, compressed schedules, telecommuting, and phased retirement).

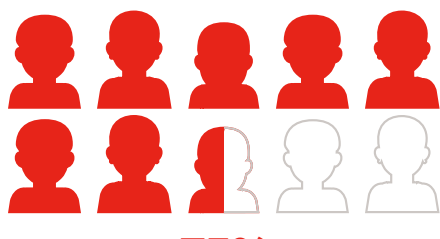

$75 \%$ 


\section{Introduction}

In the United States, family caregivers are the backbone of care support for individuals with a chronic, disabling, or serious health condition. They identify, arrange, and coordinate health care as well as services and supports; accompany their family member or friend on health provider visits; administer medications and perform complex medical and nursing tasks (such as performing wound care, giving injections, and handling medical equipment); assist with personal care (such as bathing and dressing); pay bills and deal with health insurance; and perform other vital activities to help individuals remain in their homes and communities for as long as possible.

While caregiving can be rewarding, many family caregivers of all ages experience significant physical, psychological, and financial stresses because of their caregiving role. In fact, recent research indicates that the percentage of family caregivers reporting declines in their self-rated health increased from 17 percent in 2015 to 21 percent in 2020. This is particularly prevalent among younger caregivers, those ages 18 to 49, who were more likely to report having fair or poor health as a result of their caregiving responsibilities. ${ }^{14}$ Among family caregivers age 50 and older, a 2019 EIU survey found that 87 percent reported a significant toll on their family's well-being and 65 percent felt caregiving causes significant emotional and physical strain. ${ }^{15}$ Most family caregivers experience significant out-of-pocket costs, spending $\$ 7,000$ on average, on caregiving expenses in $2016 .^{16}$

The vast majority of family caregivers also work, and balancing caregiving duties with employment and other responsibilities can be a major challenge for many. In fact, many workers experience a negative impact on their paid work as a result of caregiving. The economic consequences of reducing work hours, quitting a job to provide care, or taking an unplanned early retirement can be significant for individuals and their families as well as the broader economy.

While family caregivers are a diverse group representing all ages, racial, and socioeconomic groups, this report takes a deeper look into family caregivers age 50-plus in the U.S. This report builds on the latest AARP's Longevity Economy ${ }^{\circledR}$ outlook study (see figure 1), which found that the contributions of people 50-plus benefit society and Americans of all ages, with growing numbers of people in this age group working, paying taxes, supporting the expanding job market, giving time and money to charitable causes, and caregiving for family and loved ones. According to the Longevity Economy Outlook the annual economic contributions of the 50-plus age group will triple, from $\$ 8.3$ trillion to $\$ 26.8$ trillion by 2050 . However, had there been greater support for working family caregivers, the economic projections would be much higher.

\section{THE LONGEVITY ECONOMY® Outlook}

The Longevity Economy ${ }^{\circledR}$ Outlook measures the 50-plus population's overall contribution to GDP, employment, wages and salaries, and taxes through 2050, and analyzes their unique impact within industries. All forecasts account for the effects of COVID-19 on U.S. demographic and economic projections.

The economic contribution of people 50 -plus will be worth $\$ 12.6$ trillion in 2030; that contribution is forecast to grow to $\$ 26.8$ trillion by $2050 . .^{17}$

Accounting for the economic impact of supporting working family caregivers looks beyond this contribution. It reveals how allowing people 50-plus with family caregiving responsibilities to fulfill their economic potential in the workplace could generate additional value. ${ }^{18}$

Figure 1

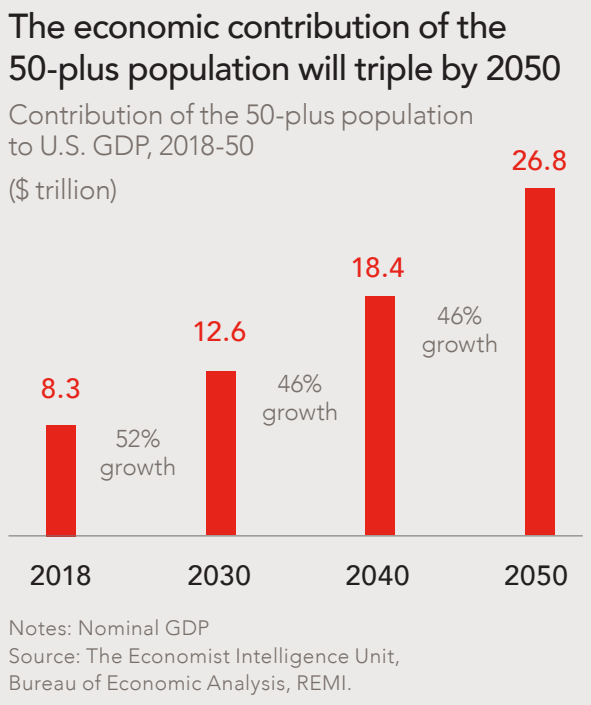

\footnotetext{
14. AARP and National Alliance for Caregiving. "Caregiving in the United States 2020." Washington, DC: AARP. May 2020. https://doi.org/10.26419/ppi.00103.001.

15. 2019 survey of 5,000 adults age 50-plus conducted by the EIU on behalf of AARP. See "Appendix 1: Notes on the methodology" for additional details about the survey methodology.

16. Rainville, Chuck, Laura Skufca, and Laura Mehegan. "Family Caregiving and Out-of-Pocket Costs: 2016 Report." Washington, DC: AARP Research, November 2016. https://doi.org/10.26419/res.00138.001

17. The Longevity Economy® Outlook (2019). https://longevityeconomy.aarp.org/.

18. The Longevity Economy ${ }^{\circledR}$ Outlook takes into account the 50 -plus population's consumption spending, its labor supply, and its tax contributions to estimate this cohort's current economic impact. The caregiving scenario estimates the potential economic impact of increased labor supply, productivity, and wages of the 50-plus population if better caregiver supports enabled caregivers to remain engaged in the workforce.
} 
This report examines how providing support to family caregivers age 50 plus to enable them to remain actively engaged in the workforce would affect the US economy. Our analysis finds that the economic impact from supporting employed family caregivers is substantial. If employed family caregivers age 50-plus have access to support in the workplace, U.S. GDP could grow by an additional $\$ 1.7$ trillion (or 5.5 percent) in 2030 and by $\$ 4.1$ trillion (or 6.6 percent) in 2050 (see figure 2). Note that all forecasts account for the effects of COVID-19 on U.S. demographic and economic projections. ${ }^{19}$
Figure 2

GDP could increase by 5.5 percent in 2030 and 6.6 percent in 2050 if working family caregivers age 50 -plus were able to remain in the workforce

Projected impact on U.S. GDP with supports for 50-plus working family caregivers (\$ trillion)

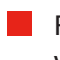

Potential impact on GDP with caregiving supports

Baseline GDP

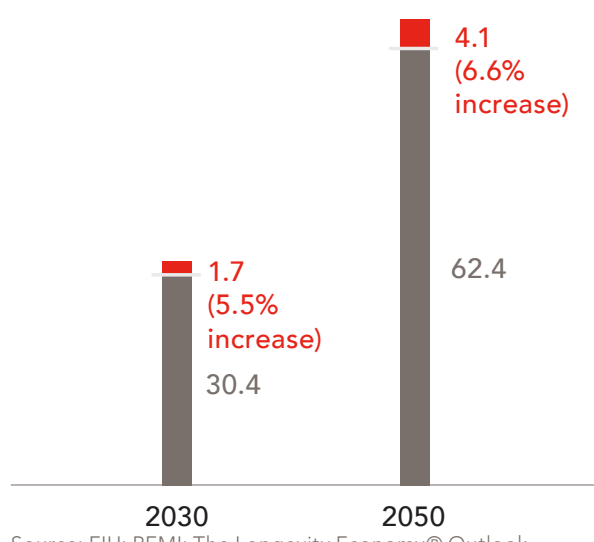

If employed family caregivers age 50 -plus have access to support in the workplace, U.S. GDP could grow by an additional $\$ 1.7$ trillion (or $\mathbf{5 . 5}$ percent) in 2030 and by $\$ 4.1$ trillion (or $\mathbf{6 . 6}$ percent) in 2050.

\section{Family caregiving and the labor force}

More than half of caregivers over age 50 are engaged in the labor force, but three in five of those have been forced to adjust or leave their job in order to provide care to family or friends.

As the U.S. population ages and individuals stay in the workforce longer, the share of working family caregivers will increase. Many older workers, including caregivers, are choosing to remain engaged in the labor force-even past traditional retirement age. Among caregivers age 65-74, 32 percent are still employed and among caregivers age 75 and older, 12 percent are still in the labor force (see figure 3). However, not enough employers are taking steps to create workplace environments that are responsive to the needs of workers who have caregiving responsibilities. ${ }^{20}$
Figure 3

More than half of caregivers age 50-plus are active participants in the labor force Percent of caregivers who are employed, by age and gender (2019)

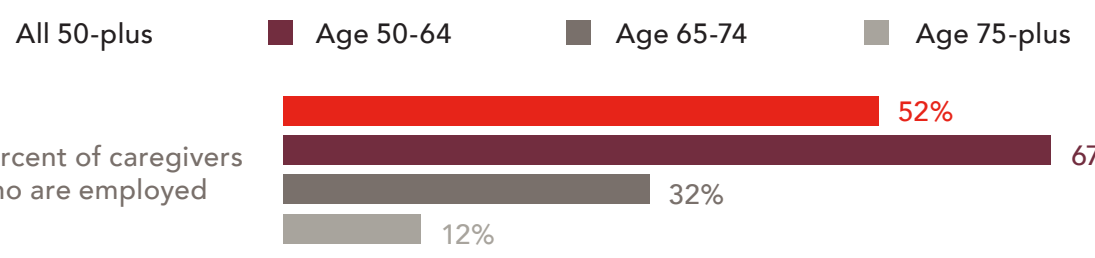

Percent of male caregivers who are employed

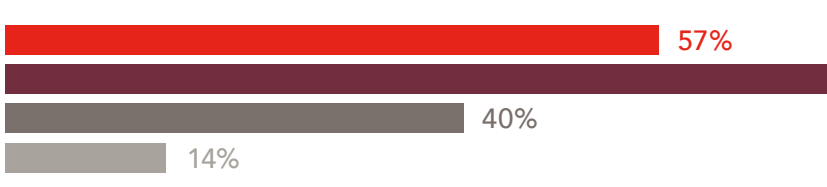

$73 \%$
Percent of female caregivers who are employed

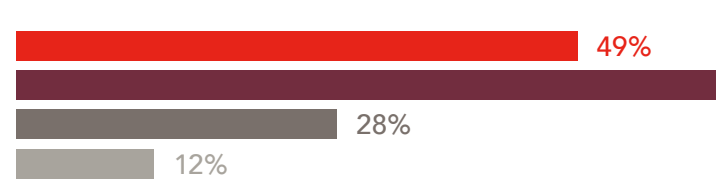

$61 \%$

Source: AARP and National Alliance for Caregiving, "Caregiving in the U.S. 2020."

Sample: Working family caregivers age 50 and older; sample size 50 -plus working

caregivers $=372,50$-plus employed women $=225$, and 50 -plus employed men $=147$. 
Most older employed caregivers report encountering difficulties balancing their work life with their care obligations.

Recent research from the National Alliance for Caregiving and AARP shows that 61 percent of employed caregivers of all ages, including those who are age 50-plus, have faced some type of workrelated consequence as a result of their caregiving responsibilities (see figure 4). ${ }^{21}$

\section{As Americans remain active in} the workforce at older ages_-and as family caregiving becomes increasingly prevalent-new norms are needed to more effectively support family caregivers in the workplace.
Work, and the workplace, is changing around the world at a rapid pace. With people living and working longer, employers are managing up to five generations at work on any given day. ${ }^{22}$ Historically low unemployment rates and shifting demographic trends create a strong argument for the intentional inclusion of workers across the age spectrum and throughout the talent lifecycle-from the youngest entrants to the oldest contributors. However, outdated beliefs about aging and assumptions based on ageist stereotypes often persist in ways that shape organizational culture and practices. Nevertheless, many employers recognize that their older employees are keen to continue working. In a 2017 employer survey, 72 percent agreed that many of their employees intended to work past the age of 65 . And 80 percent of respondents stated that their companies were supportive of this decision. ${ }^{23}$

\section{In a 2017 employer survey, 72 percent agreed that many of their employees intended to work past the age of 65 .}

Figure 4

Sixty-one percent of 50-plus family caregivers in the workforce have been impacted by their care responsibilities, with more than half of working caregivers coming in late, leaving early, or taking time off to provide care

Percent of working family caregivers over age 50 who have experienced adverse consequences

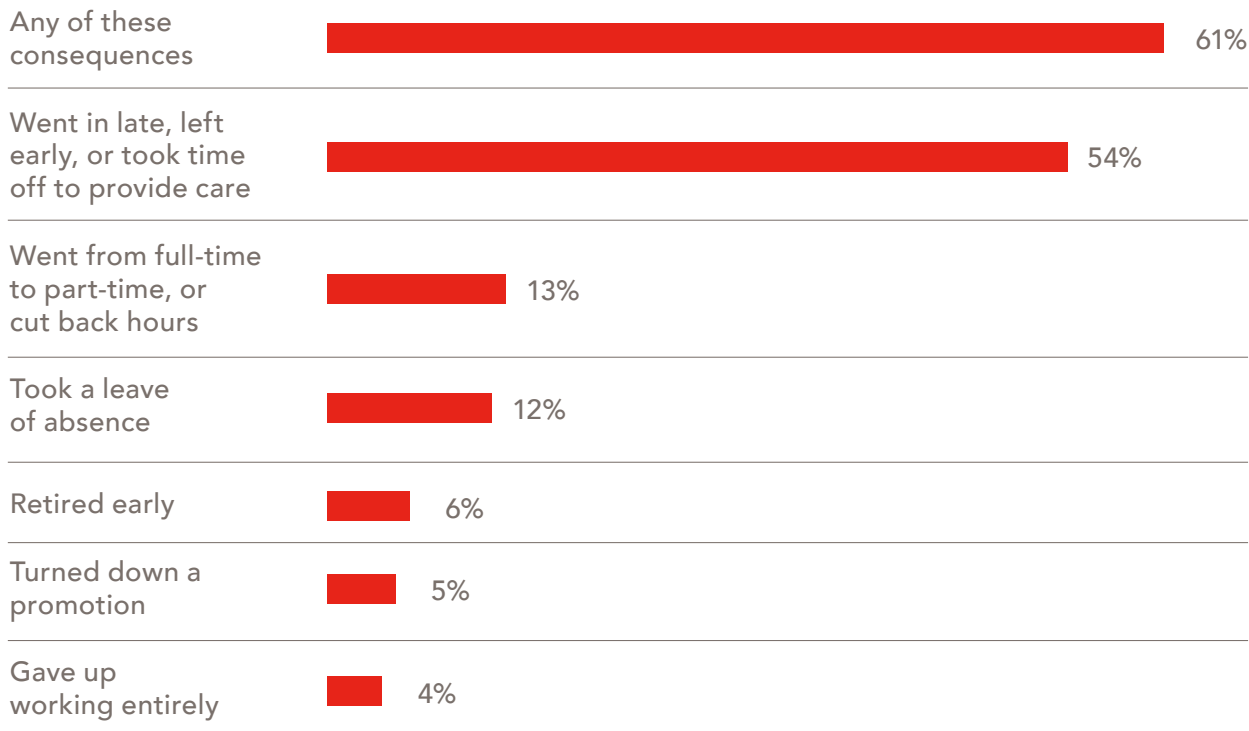

Received a warning about performance or attendance 
Employees with family caregiving responsibilities, however, often struggle to balance their responsibilities and remain in the labor force. In a 2019 EIU survey of the 50-plus population, those without family caregiving responsibilities who were still working past age 65 said they planned to work an average of 5.1 additional years before retiring (see figure 5). For those with family caregiving responsibilities who still were working, this number dropped to 4.9 years. (Each sample had the same average age of 68.1 years.) The difference may seem small, but this sample includes only those who have decided to keep working. In contrast, for caregivers who opt to leave the labor force, such a decision typically means multiple years of foregone employment and lost wages.

While some employers and governments have taken steps to accommodate workers' family caregiving responsibilities, there is still room for improvement. Many family caregivers of all ages, including older caregivers, are still faced with difficult decisions about whether to reduce their hours, turn down a promotion, take a pay cut, use paid or unpaid family leave, or drop out of the labor force.

A 2019 EIU survey ${ }^{24}$ shows
that more than 75 percent
of those who retired
early because of family
caregiving responsibilities
would have remained in
the workforce longer if they
had access to alternative
work arrangements such
as flexible hours/shifts,
telecommuting, compressed
schedules, paid leave, or
phased retirement.

Figure 5

\section{Family caregivers who choose to keep working past age 65 plan to retire sooner than those without caregiving responsibilities}

Number of years until planning to retire, for working family caregivers and non-caregivers age 65-74

Family caregivers who choose to

work past age 65

4.9
Non-caregivers who choose to work past age 65

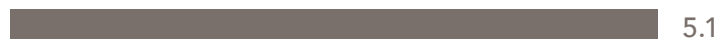

5.1
4.5

5
5.5

Source: The Economist Intelligence Unit 2019

Sample: Average age of non-caregivers $=68.1$ and caregivers $=68.1$; sample size of non-caregivers $(n=244)$ and caregivers $(n=69)$.

Note: Axis begins at 4 years.

These challenges not only hurt working family caregivers, but they also deprive workplaces of the benefits provided by their productivity. In 2020, the median tenure of workers ages 55 to 64 in their current jobs was 9.9 years, more than three times that of workers aged 25 to 34 years. ${ }^{25,26}$ As the workforce has become more diverse, multigenerational workforces also help foster productive environments and maximize knowledgesharing. In a recent AARP survey, 77 percent of employees stated that having older colleagues creates an opportunity to learn new skills. ${ }^{27}$

Workplaces have been slow to embrace flexibility, although that may be changing. Research from 2017 by the Transamerica Center for Retirement Studies showed that just 39 percent of employers accommodated flexible work schedules and arrangements, initiatives that would help older family caregivers stay engaged in the workforce. ${ }^{28}$ According to a recent survey looking ahead to the post-COVID workplace, however, 83 percent of companies in the U.S. reported they are considering implementing flexible work at a greater scale after the pandemic. Still, two-thirds of respondents expressed concerns about managers' attitudes and skills in applying such changes to flexibility norms moving forward. ${ }^{29}$ These issues underscore the continuing need to create workplace environments-both through initiatives and policies as well as proper implementation (e.g., training of managers) — that are responsive to the needs of family caregivers.

24. 2019 survey of 5,000 adults age 50-plus conducted by the EIU on behalf of AARP. See "Appendix 1: Notes on the methodology" for additional details about the survey methodology.

25. Bureau of Labor Statistics, "Employee Tenure Summary" (September 22, 2020). https://www.bls.gov/news.release/tenure.nr0.htm.

26. AARP, "A Business Case for Workers Age 50-plus: A Look at the Value of Experience" (2015).

https://www.aarp.org/content/dam/aarp/research/surveys_statistics/general/2015/business-case-workers-age-50plus.doi.10.26419\%252Fres.00100.001.pdf.

27. AARP, "Older Workers Valued for Their Experience, Research Shows" (2019). https://www.aarp.org/work/working-at-50-plus/info-2019/multigenerational-workforce-survey.html.

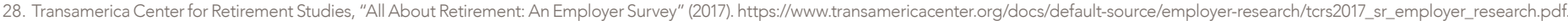

29. MERCER, "Global Survey \#6: In the United States, how are companies flexing for the future and returning to the workplace?" https://app.keysurvey.com/reportmodule/REPORT5/

report/41506990/41214286/c523180dbe03fd9f349de61e08091c7d?Dir=\&Enc_Dir=9c3e87c1\&av=|xnIBAm77ac\%3D\&afterVoting=6d40c87c1307\&msig=0285f81640c6488d88ee37dc1785f3ce.

The Economic Impact of Supporting Working Family Caregivers 


\section{The effects of family caregiving across demographic groups}

From retiring early to accepting jobs with lower pay or fewer hours, 50-plus employed family caregivers have difficulty thriving in the workplacebut not all demographic groups are affected equally.

Our research shows that many of these challenges tend to negatively affect the labor force participation of caregivers. Women, in particular, make up the majority of family caregivers (among caregivers age 50-64, 65 percent are women), and they also tend to suffer higher rates of adverse work-related consequences than men (see figure 6).

On another note also regarding gender, while women more frequently care for two or more adults and are often primary caregivers, ${ }^{30}$ men tend to spend more years in an average caregiving role (see figure 7). ${ }^{31}$

While about 6 in 10 family caregivers of all ages across all race/ethnicity groups are employed, African American caregivers are the most likely to be in the labor force (64 percent), followed by White (62 percent), Hispanic (60 percent), and Asian American (59 percent) family caregivers. ${ }^{32}$ Among family caregivers age 50-plus, African American and White family caregivers tend to remain in the workplace at the highest rates, with Hispanics, Asians, and Pacific Islanders less likely to work while providing care (see figure 8).

Figure 6

Older employed women are more likely to cut back on

Men

Women hours, take a leave of absence, or drop out of the labor force than men due to caregiving responsibilities

Prevalence of experiencing work-related consequences to caregiving, by gender

Cut back on hours $10.0 \%$

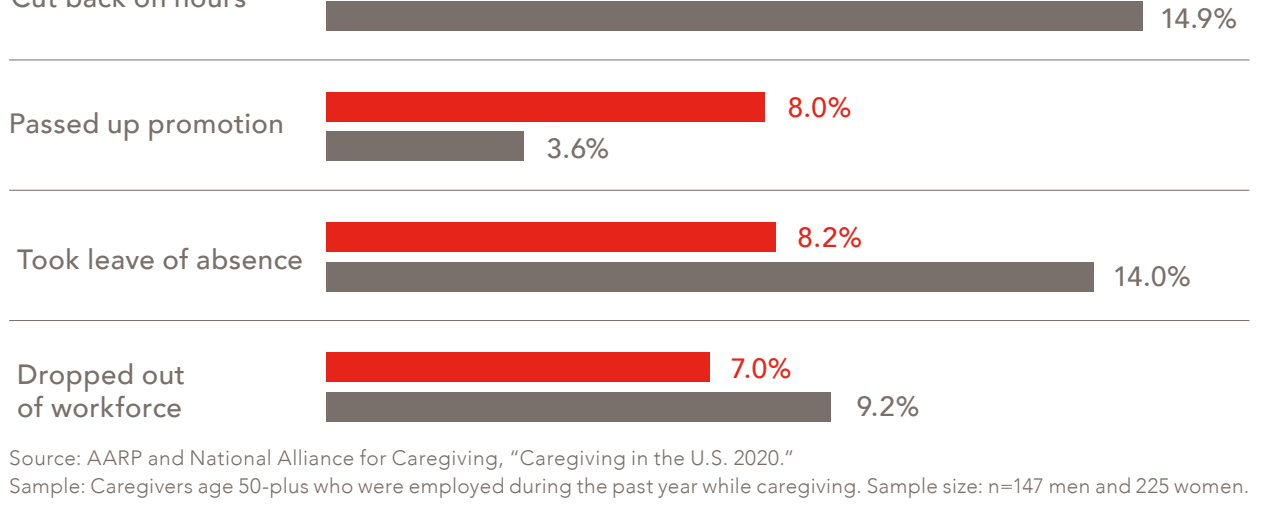

Figure 7

The average 50-plus family caregiving role tends to last longer for men than for women

Average duration of family caregiving role, by age and gender (years)

\section{Average duration of caregiving roll \\ (Years)}

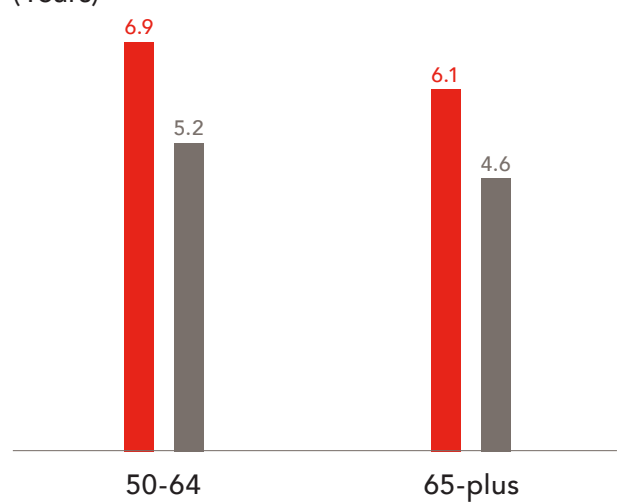

Source: AARP and National Alliance for Caregiving, "Caregiving in the U.S. 2020." Sample: Caregivers age 50-plus; sample sizes range from $n=98$ for age 65 -plus men to $n=306$ for age 50-64 women.
Figure 8

African Americans and Whites are much more likely to be employed while engaging in family caregiving than Hispanics and Asians/Pacific Islanders

Employment rates for current family caregivers age 50-plus caring for those age 18 and older, by race/ethnicity)

Employed (\%)

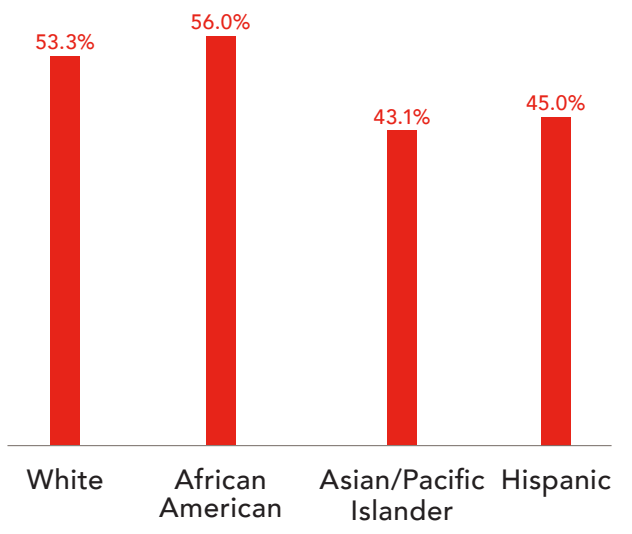

Source: AARP and National Alliance for

Caregiving, "Caregiving in the U.S. 2020."

Sample: Current family caregivers age 50-plus: sample sizes: White $(n=501)$, African American $(n=90)$, Asian/Pacific Islander $(n=34)$, Hispanic $(n=75)$. 
Across all racial/ethnic groups, more than 60 percent of employed caregivers age 50 and older have access to paid sick days, and more than 50 percent have access to flexible work hours. Workers age 50 and older (64 percent) were more likely than those age 18 to 34 (39 percent) to report the availability of paid sick days. ${ }^{33}$ However, very few family caregivers have access to paid family leave, telecommuting, or remote work, especially Hispanics (see figure 9), although this trend may change in the wake of the COVID-19 pandemic. Recent data from the Bureau of Labor Statistics (December 2020) showed that only 14 percent of Hispanic workers and 19 percent of African American workers had teleworked in the previous four weeks because of the pandemic, compared to 23 percent of White workers and 39 percent of Asian workers. ${ }^{34}$

Finally, caregiving responsibilities affect some groups more than others in the workplace. Among all 50-plus family caregivers, African Americans report experiencing more discrimination at work as a result of their family caregiving responsibilities, whereas Asian and Pacific Islanders report the lowest rates of discrimination (see figure 10). Such findings speak to the importance of ensuring that workplace opportunities should not be limited by stereotypes, misperceptions, or unwarranted assumptions about caregiving. Although some parts of the U.S. have laws that protect family caregivers from workplace discrimination (e.g., localities across 21 states have provisions that address family responsibility), only two states (Delaware and the District of Columbia) specifically include family caregivers as a protected classification under state law. ${ }^{35}$
Figure 9

\section{Paid sick days and flexible work hours are common family caregiving supports across all races/ethnicities}

Access to caregiving supports from employer, by race/ethnicity

\begin{tabular}{|c|c|c|c|c|}
\hline & White & $\begin{array}{r}\text { African } \\
\text { American }\end{array}$ & $\begin{array}{r}\text { Asian/ } \\
\text { Pacific } \\
\text { Islander }\end{array}$ & Hispanic \\
\hline Paid sick days & $62 \%$ & $70 \%$ & $61 \%$ & $62 \%$ \\
\hline Flexible work hours & $55 \%$ & $67 \%$ & $53 \%$ & $63 \%$ \\
\hline Paid family leave & $39 \%$ & $43 \%$ & $49 \%$ & $45 \%$ \\
\hline Information/assistance programs & $27 \%$ & $29 \%$ & $22 \%$ & $38 \%$ \\
\hline \multirow[t]{2}{*}{ Telecommuting or remote work } & $24 \%$ & $29 \%$ & $29 \%$ & $21 \%$ \\
\hline & $\mathrm{n}=215$ & $\mathrm{n}=44$ & $n=29$ & $\mathrm{n}=32$ \\
\hline
\end{tabular}

Source: AARP and National Alliance for Caregiving, "Caregiving in the U.S. 2020."

Sample: Employed (either part-time or full-time) family caregivers (excluding self-employed).

Figure 10

\section{African Americans report a higher occurrence of penalization or discrimination at work due to their caregiving obligations \\ Percentage of 50 -plus family caregivers, by race/ethnicity}

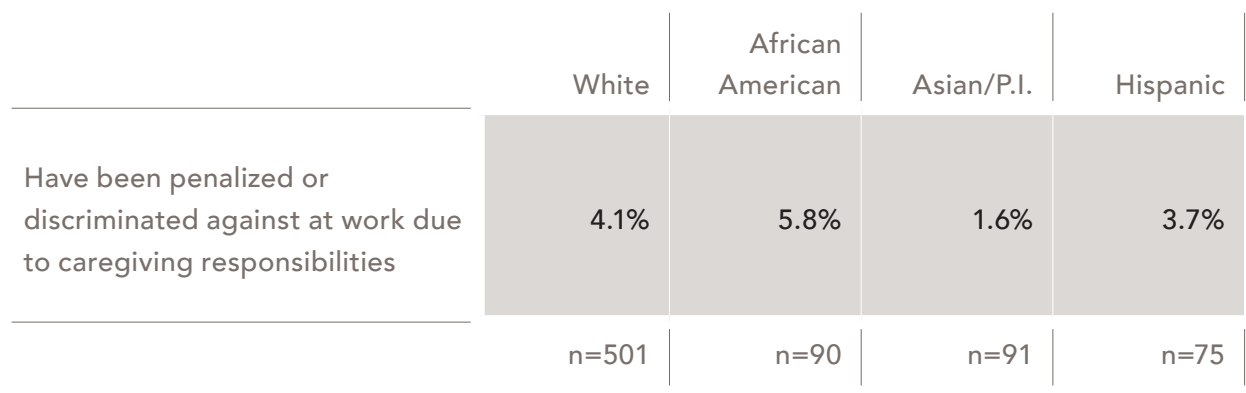

Source: AARP and National Alliance for Caregiving, "Caregiving in the U.S. 2020." Sample: Current family caregivers age 50-plus. 


\section{Measuring the economic impact of supporting employed family caregivers}

Given the workplace obstacles faced by family caregivers, this AARP report ${ }^{36}$ takes a deeper look into the potential economic gains that could result if family caregivers age 50 -plus were able to participate more actively in the economy. These gains would be greater if caregivers under 50 were also taken into account.

Our model considers how such supports may help working caregivers who have been affected in the following four ways:
- Reducing hours worked: We look at the incidence of people age 50 plus either cutting back their hours or moving from full-time to part-time work in order to accommodate their family caregiving responsibilities. This analysis considers what would happen if these workers were not compelled to reduce their workforce participation.

- Taking unpaid leaves of absence: We explore the incidence of 50 plus workers taking unpaid leaves of absence to attend to family caregiving duties in order to understand what might occur if they were able to take paid leave instead, or otherwise remain employed to their full capacities and be compensated accordingly.
- Passing up a promotion or an opportunity for more pay: We look at the incidence of 50-plus family caregivers being forced to turn down opportunities for career advancement or wage growth in order to understand what would happen if they had the same job opportunities as their peers.

\section{- Dropping out of the labor force:} We explore the incidence of 50 plus workers who either drop out of the labor force or retire early as a result of family caregiving obligations in order to understand what would happen if they could have remained productively engaged in the labor force during that time.

\section{Defining our scenario}

With more and more Americans remaining active in the workforce past traditional retirement age, coupled with increases in the prevalence of family caregiving, older adults simultaneously working while providing care is fast becoming a norm.

In this context, the benefits of encouraging 50-plus family caregivers to remain in the workforce at their full capacity are potentially enormous and will only grow larger in the future.
Our scenario explores the potential increase to the economy if greater support were provided for family caregiving through workplace initiatives and government policies, including both financial and non-financial assistance. We model how the labor supply, productivity, and wages and salaries of caregivers 50-plus would increase if they were not compelled to reduce their employment, take pay cuts or unpaid leaves of absence, or drop out of the labor force.
The scenario models the potential boost to GDP, employment, and wages and salaries through 2050 if employed family caregivers were better supported, while also analyzing the increase within and across industries. Forecast results are included for three different future growth paths for family caregivers. 
Forecasting the growth of family caregivers in the U.S.

From 2014 to 2019, the number

of family caregivers over age

50 grew from 22 to 26 million.

By 2050, we estimate the

number will reach 47 million. ${ }^{37}$

To estimate the number of adult

Americans who will need care over the next 30 years, we looked to the growing size of the 80-plus population (those most at risk of needing assistance with services and supports) as a proxy indicator. The 80-plus cohort is expected to expand by 144 percent by 2050, rapidly outpacing those age 45-64-the primary age for caregivers-which will only see a 15 percent increase.

This decline in this "caregiver support ratio," as it is called, signals a squeeze in the number of potential family caregivers available to care for a swelling older population. ${ }^{38,39}$

In a conservative scenario, this would mean significantly fewer family caregivers per recipient, while in a more extreme scenario, a much greater share of the population would need to be engaged in family caregiving (see below for more details). In reality, we are likely to end up somewhere in the middle.

Since future family caregiver dynamics are uncertain, we have developed a broad range of forecasts for this scenario that captures multiple potential paths for the future number of family caregivers in the U.S. (see figure 11).

For further details about the development of our forecast assumptions, please see Appendix 1.

Figure 11

High-end:

Liberal estimate for expansion in caregiving

- A much greater share of the population engaged in caregiving

\section{Core forecast:}

A middle-ground estimate

- A mix of fewer caregivers per recipient but a greater share of the population engaged in caregiving

\section{Low-end:}

Conservative estimate for growth in caregiving

- Significantly fewer caregivers per recipient

\section{Under our core forecast, there will be 47 million 50 -plus family caregivers in 2050 in the U.S.}

Growth in total family caregivers over age 50 under three scenarios, compared with 80-plus population growth

(Percentages refer to the share of the 50-plus population engaged in family caregiving.)

\section{High-end forecast Core forecast Low-end forecast}

80 -plus population (indicative of potential growth in adult care recipients)

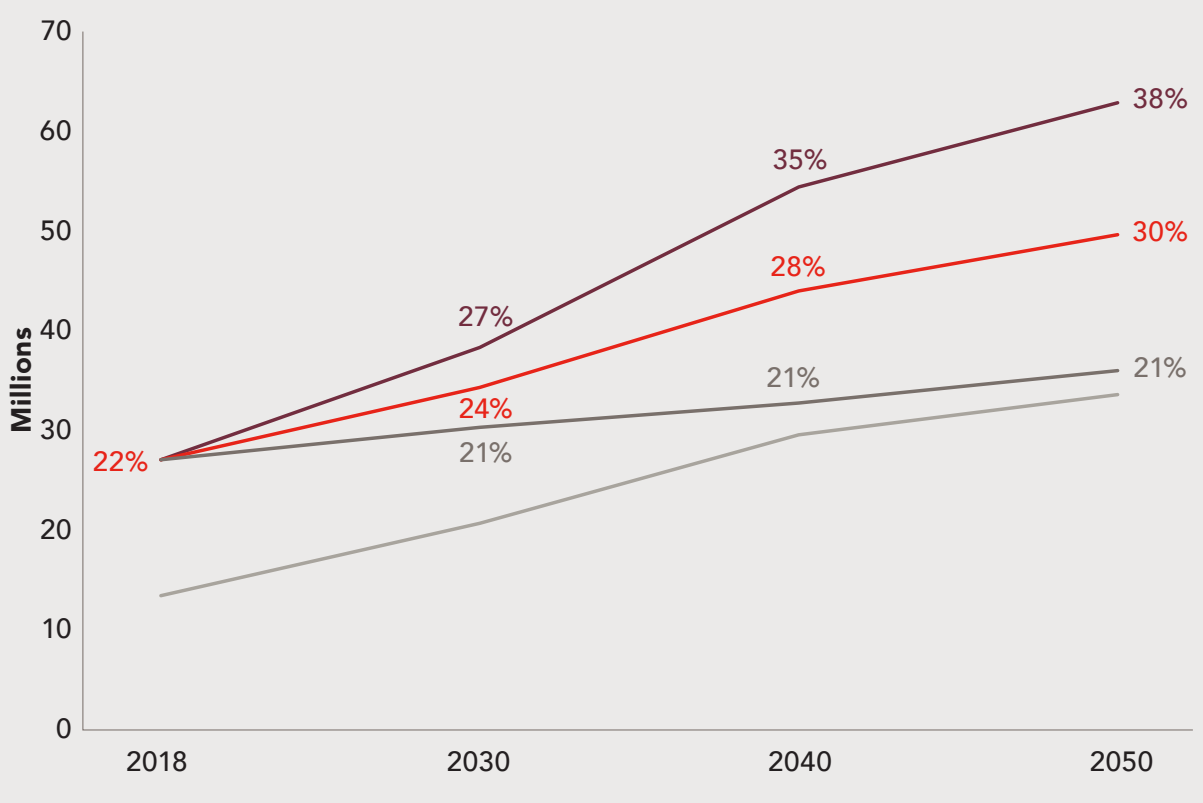

Source: The Economist Intelligence Unit, REMI, AARP and National Alliance for Caregiving's "Caregiving in the U.S. 2020."

37. This is the estimate under our core forecast. Different assumptions_as detailed in this section—would lead to our low-end forecast ( 34 million) or our high-end forecast ( 59 million).

38. Donald Redfoot, Lynn Feinberg, and Ari Houser, "The Aging of the Baby Boom and the Growing Care Gap: A Look at Future Declines in the Availability of Family Caregivers." 2013. https://www.aarp.org/content/dam/aarp/research/public_policy_institute/ltc/2013/baby-boom-and-the-growing-care-gap-insight-AARP-ppi-Itc.pdf.

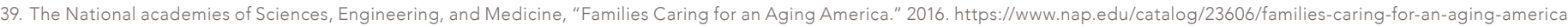


We found that supporting 50-plus caregivers' ability to participate in the workforce could generate an additional \$1.7 trillion in GDP in 2030, a figure equivalent to New York's total economy and larger than Florida's. ${ }^{40}$ The potential boost to GDP could rise to $\$ 4.1$ trillion in 2050 , an increase equal to California and Florida's current economies together (see figure 12). ${ }^{41}$

In addition, improving assistance for 50plus working caregivers could support 10.7 million jobs - a 5.2 percent increase in total jobs-for the entire U.S. working population in 2030, and boost wages and salaries by $\$ 1.1$ trillion (see figure 12 ). In 2050, these figures would rise to 13.1 million jobs and $\$ 2.5$ trillion in wages and salaries. ${ }^{42}$

The results presented above reflect our core forecast for the future number of family caregivers. However, even under a conservative outlook, in which the share of the population engaged in family caregiving does not expand, the economic impacts would still reach $\$ 3.4$ trillion in 2050. It is important to note that the economic impacts would be much larger if we accounted for family caregivers under 50 .

Figure 12

Supporting 50-plus working family caregivers could generate an additional $\$ 4.1$ trillion increase to the U.S. economy in 2050

Overall increase to GDP, jobs, and wages and salaries in 2030, 2040, and 2050 under our core forecast

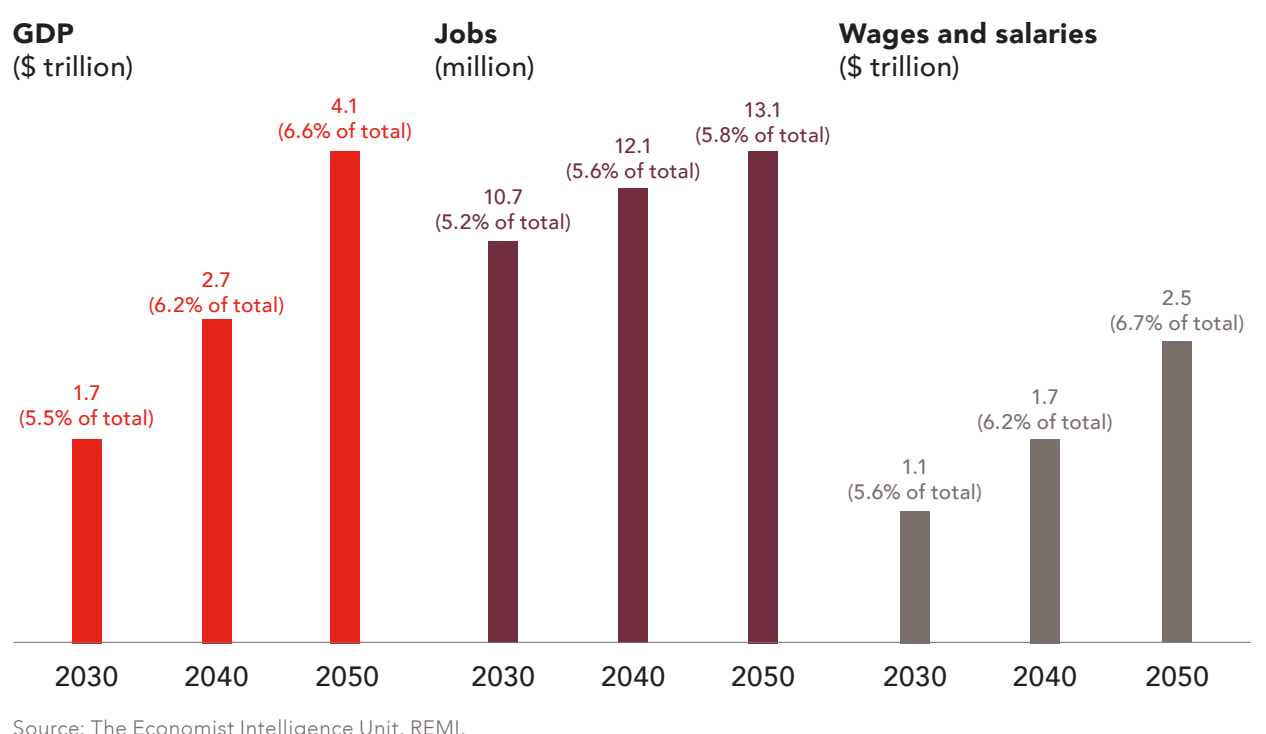

Figure 13

Even in a scenario with conservative growth of 50-plus family caregivers, the impact on GDP would still reach $\$ 3.4$ trillion in 2050

Increase to GDP under low, core, and high outlooks for the number of 50 -plus family caregivers (\$ trillions)

High-end forecast "Liberal expansion in caregiving"

Core forecast
Low-end forecast "Conservative growth in caregiving"

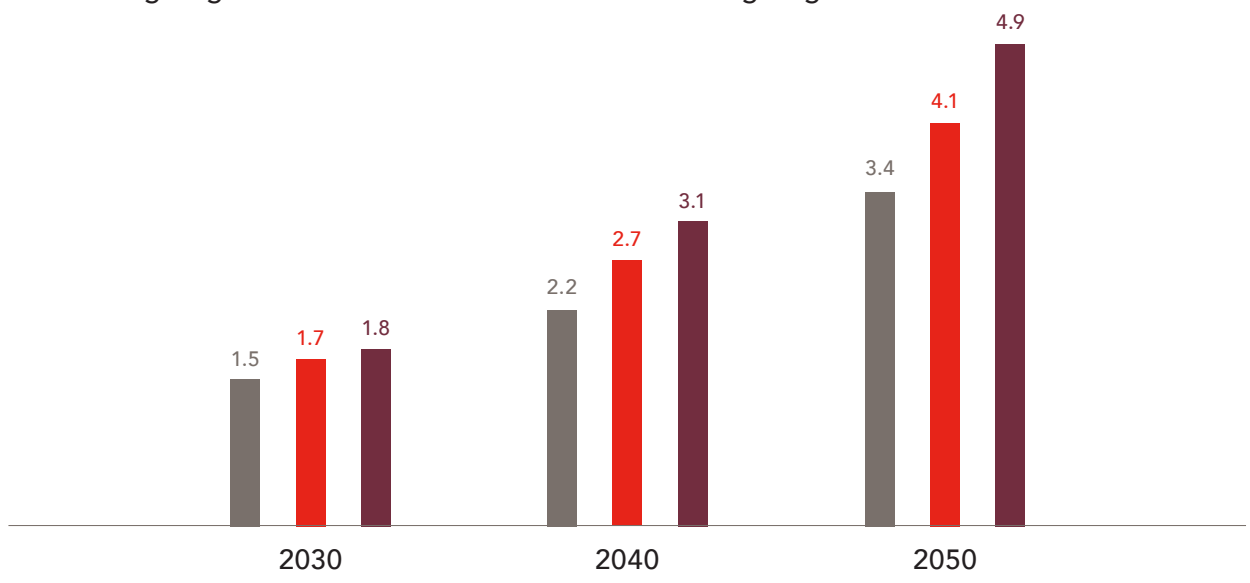

Source: The Economist Intelligence Unit, REMI.

40. Bureau of Economic Analysis, "Gross Domestic Product (GDP) summary."

41. These estimates reflect the potential impact under our core forecast.

42. These estimates reflect the potential impact under our core forecast. 
Under the core scenario, the greatest effect would be felt in higher-productivity sectors, including technology and automotive manufacturing, which are well-placed to capture the benefits of an increasingly engaged labor force. In 2030, all industries could see an average boost of 5.5 percent in value added. By 2050, under our core forecast, the technology and automotive manufacturing sectors could see a 12 percent increase (see figure 14). The large growth potential in these sectors may stem from their efficient use of additional labor productivity, although future developments such as autonomous vehicles, ridesharing, and automation can make long-term predictions uncertain.

Figure 14

The technology and automotive manufacturing sectors would experience the largest benefit from improved employed family caregiver supports

Percentage increase to GDP under our core forecast scenario, by select industry and year

2030

2040

2050

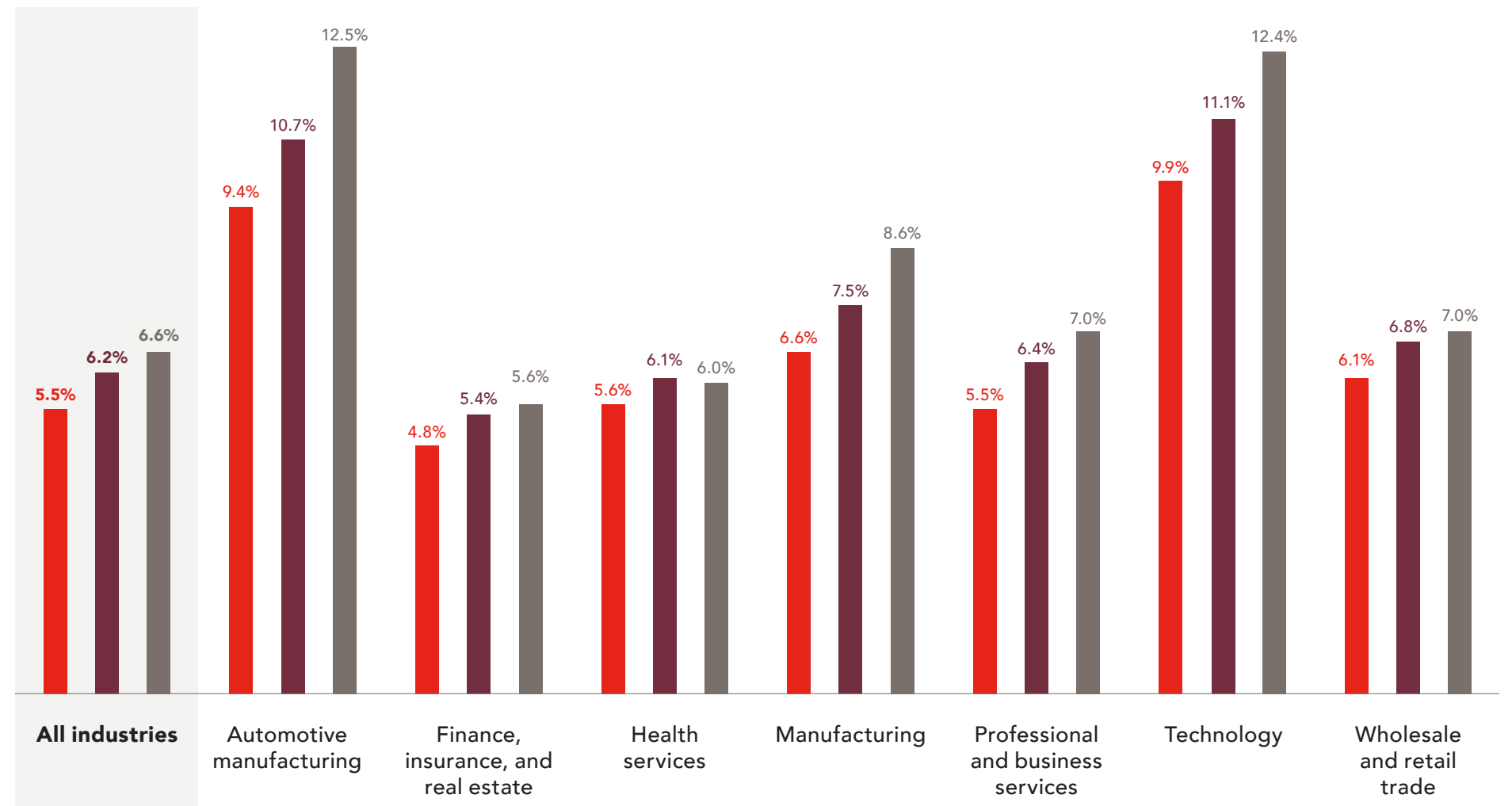

Source: The Economist Intelligence Unit, REMI. 
Benefits to consumer spending would also be generated across products and services. Sectors that could experience the biggest increases in spending in 2050 under our core forecast would be financial services and insurance (9.5 percent), transportation services (9 percent), and technology (8.7 percent). On average, all categories would see a 6 percent increase in 2050 (see figure 15).

Figure 15

\section{Spending across categories would see an average 6 percent boost in 2050 under the scenario's core forecast}

Impact on consumption spending, 2050 (\% of baseline consumption spending)

Core forecast

High-end forecast "Liberal expansion in caregiving"
口.

Low-end forecast
"Conservative growth

All commodities

Health care

Leisure and

hospitality

Housing and utilities and parts

Financial

services and

insurance

Groceries

Other

services

Technology

Clothing and

footwear

Other non-

durable goods

Education

services

Transportation

services

Other durable goods
Motor vehicles

$4.9 \%$

$6.0 \%$

$7.0 \%$

$5.3 \%$

$6.5 \%$

$7.6 \%$

$5.8 \%$

$7.2 \%$

$8.4 \%$

$3.2 \%$

$3.9 \%$

$4.6 \%$

$6.0 \%$

$7.4 \%$

$8.7 \%$

$7.7 \%$

$9.5 \%$

$11.1 \%$

$2.9 \%$

$3.6 \%$

$4.2 \%$

$4.5 \%$

$5.5 \%$ $6.4 \%$

Source: The Economist Intelligence Unit, REMI.

Note: Other services include professional services, personal care and clothing services, social services and religious activities, and postal and delivery services. Other non-durable goods include food furnished to employees (including military), household supplies, personal care products, tobacco, food produced and consumed on farms, and net expenditures abroad by U.S. residents. Education services include spending on education across all members living in the same household (consumption expenditures are recorded at the household level). Other durable goods include jewelry and watches, luggage, and similar personal items. 
Our analysis finds that-of the four labor market effects we examined (see Figure 16), family caregivers dropping out of the workforce represent the largest potential cost to the economy. This effect is especially pronounced for women-particularly those with low incomes-who are nearly three times more affected than men by labor force dropout and early retirement.

Likewise, across all four labor market effects, women suffer more adverse consequences than men as a result of family caregiving.
Figure 16

Preventing family caregivers from dropping

Men

Women out of the labor force has the biggest potential to boost the economy

Percentage share of the total economic impact attributed to each effect, by gender

Reducing hours worked $4 \% 10.1 \%$

Taking unpaid leave

$0.2 \% \mid 0.4 \%$

Passsing up promotion

$0.2 \% \mid 0.3 \%$

Dropped out of workforce

Source: The Economist Intelligence Unit; REMI

\section{Calculating the economic benefits: How we did it}

To estimate the potential increase to the U.S. labor force participation - and the economy under a scenario where 50 -plus working caregivers are more fully supported, we calculated four different ways their labor force participation is affected by caregiving:

- Cutting back on hours worked

- Taking unpaid leaves of absence

- Passing up promotions or opportunities for more pay

- Dropping out of the labor force

The resulting increase to the 50-plus related increases in labor productivity and wages that would result-were input into a dynamic forecasting model from Regional Economic Models, Inc. (REMI) to determine economic impact.

Our approach models labor supply and productivity to help establish a GDP aspiration by providing more comprehensive supports for family caregivers. We assume that demand-side factors will not inhibit the economy from accommodating the jobs created by the increase in labor supply of 50-plus caregivers. Our scenario assumes that the entire 50-plus family caregiver population that is currently unable to fully participate in the economy as a result of these factors is now employed to full desired potential, based on the assumptions described in Appendix 1: Note on the methodology. It represents the maximum economic impact that could be achieved from improving the workforce participation of family caregivers in the U.S. labor market. 


\section{Capturing the benefits of better support for family caregivers}

As has been shown in this report thus far, providing better supports for working family caregivers of all ages, including those age 50 and older, is not only necessary given the current demographic shifts occurring in the U.S., but also because doing so will increase the economic contribution of family caregivers, benefiting businesses and fueling economic growth.

\section{What supports are needed to capture the potential?}

Family caregiver supports can take many forms, ranging from financial to nonfinancial resources and from business to government-sponsored initiatives.

Financial supports include mechanisms such as paid family leave, paid sick leave, respite services, funding for long-term care insurance, government subsidies and credits, other state-sponsored programs, and employersponsored backup care. Many of these supports are among the most useful resources for family caregivers, as illustrated in a 2019 EIU survey in which the majority of respondents rated them as "very helpful" (see figure 17, which provides a glimpse into which resources and supports are most valued by family caregivers).

Paid family leave, also known as "family caregiver leave" or "family leave insurance," allows employees to take time off from work to address family caregiving needs without a substantial loss of income or employment. Yet, only nine states (California, Connecticut, Maine, Massachusetts, New Jersey, New York, Oregon, Rhode Island, and Washington) and the District of Columbia offer, or will offer in the near future, paid family leave. ${ }^{43}$

Having paid sick leave and being able to use it for family caregiving becomes more important during a pandemic. Unfortunately, at present, paid sick leave is not provided under federal law. At the state and local level, more than one-third of states (20) have statewide or local laws mandating paid sick days for employees. Of those 20 states with either statewide or local paid sick leave laws, 13 enacted or expanded their policies in the past three years. ${ }^{44}$ As for employer-provided paid sick leave, AARP's caregiving survey shows that over half of working family caregivers reported that their employers offer it. ${ }^{45}$ However, breaking down paid sick leave by occupation, employer size, and wage reveals wide gaps in access and availability. ${ }^{46}$
Some of the most innovative programs that provide financial supports include Hawaii's Kupuna Caregivers Assistance Act, which makes weekly vouchers available to employed family caregivers to hire long-term care services for older loved ones, ${ }^{47}$ and Washington's LongTerm Care Trust Act, under which family caregivers can receive funds to help with the high costs of long-term care. This assistance is disbursed through a public insurance program that is funded through a payroll deduction. ${ }^{48}$ These tools (government programs, support payments, and care insurance) are valuable resources for family caregivers, with 47 percent to 59 percent of respondents from the EIU survey agreeing that they have been "very helpful."

\section{Non-financial supports include flexible working options, employee Assistance Programs (EAPs) and other information services, expanded coverage of the Family and Medical Leave Act (FMLA), training on care tasks, and anti- discrimination protections for employed caregivers.}

43. For more information, please see https://www.aarp.org/caregiving/financial-legal/info-2019/workers-family-medical-leave-act.html.

44. A list of states and localities that provide paid sick leave include Arizona, California, Colorado, Connecticut, Delaware, District of Colombia, Illinois, Maine. Maryland, Massachusetts, Michigan, Minnesota, Nevada, New Jersey, New Mexico, New York, Oregon, Pennsylvania, Rhode Island, Texas, Vermont, and Washington.

For more information, please see AARP Public Policy Institute, "Long-Term Services and Supports State Scorecard: 2020 Edition".

http://www.longtermscorecard.org/ /media/Microsite/Files/2020/LTSS\%202020\%20Reference\%20Edition\%20PDF\%20923.pdf.

45. AARP and National Alliance for Caregiving. "Caregiving in the United States 2020." Washington, DC: AARP. May 2020. https://doi.org/10.26419/ppi.00103.001.

46. Bureau of Labor Statistics, "Employee Benefits in the United States_March 2019," news release, September 19, 2019.

https://www.bls.gov/news.release/pdf/ebs2.pdf.https://www.bls.gov/ncs/ebs/benefits/2019/ownership/civilian/table31a.pdf.

47. Emily S. McCarthy, "A Policy Analysis of the Kupuna Caregivers Act: Addressing the Needs of Working Caregivers in Hawaii." 2018. https://uknowledge.uky.edu/cgi/viewcontent.cgi?article=1185\&context=cph_etds.

48. Victoria Sackett, AARP, "Some States Easing Financial Burden on Caregivers." https://www.aarp.org/caregiving/financial-legal/info-2018/caregiver-state-laws-fd.html.

The Economic Impact of Supporting Working Family Caregivers 
Employed family caregivers put a high value on options like flexible scheduling or the ability to work from home. In fact, the category of flexible work optionssuch as flexible hours/shifts, compressed schedules, telecommuting, and phased retirement-was the most helpful type of resource for older employed family caregivers (see figure 17).

While some states have independently expanded FMLA coverage, federal law only applies to the care of newborn children and seriously ill family members. However, 10 states have gone beyond the federal minimum FMLA by covering family members outside the scope of federal protections, extending the length of leave, or covering smaller employers. ${ }^{49}$ Among the 10 states, the District of Columbia continues to have the most robust protections for family and medical leave. ${ }^{50}$

Among employed family caregivers of all ages, only a quarter reported that their employer offers programs like EAPs or information services (26 percent). ${ }^{51}$ However, nine in ten family caregivers consider these kinds of informational assistance programs to be helpful, with nearly half saying they are "very helpful" (see figure 17). ${ }^{52}$

Anti-discrimination protections are a final important policy goal for enabling the labor force participation of all types of caregivers, whether they care for children, older adults, or ill or disabled family members. A number of states and localities have already enacted their own anti-discrimination measures to protect employed family caregivers. ${ }^{53}$
Figure 17

Family caregivers age 50-plus say flexible work/leave options, formal assistance services and credits, and trainings on proper care are most helpful

Percentage of all family caregivers who say each support or resource is "very helpful"

Flexible work options

Family medical

leave act

Technology tools

for telework

Government programs or credits

$59 \%$

Respite services

$56 \%$

Paid sick leave

$56 \%$

Training on

medical tasks

$55 \%$

Paid leave

$52 \%$

Family support

payments

$50 \%$

\section{Information on}

disease/conditions

$49 \%$

Private long-term

care insurance

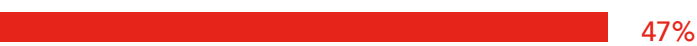

Unpaid leave

$45 \%$

Financial/legal

information

$37 \%$

Tax incentives

$37 \%$

Source: The Economist Intelligence Unit 2019

Note: Government program or credits include Medicaid, cash-and-counseling, waiver benefits, and the

Veteran-Directed Home and Community-Based Services Program such as meals and transportation.

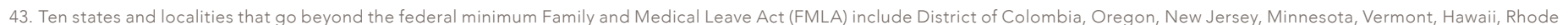
Island, Connecticut, Maine, and Wisconsin. For more information, please see AARP Public Policy Institute, "Long-Term Services and Supports State Scorecard: 2020 Edition".

http://www.longtermscorecard.org/ /media/Microsite/Files/2020/LTSS\%202020\%20Reference\%20Edition\%20PDF\%20923.pdf.

50. AARP Public Policy Institute, "Long-Term Services and Supports State Scorecard: 2020 Edition".

http://www.longtermscorecard.org/ /media/Microsite/Files/2020/LTSS\%202020\%20Reference\%20Edition\%20PDF\%20923.pdf.

51. AARP and National Alliance for Caregiving. "Caregiving in the United States 2020." Washington, DC: AARP. May 2020. https://doi.org/10.26419/ppi.00103.001.

52. 2019 survey of 5,000 adults age 50-plus conducted by the EIU on behalf of AARP. See "Appendix 1: Notes on the methodology" for additional details about the survey methodology.

53. For more information, please see https://www.abetterbalance.org/resources/family-status-and-caregiver-discrimination-around-the-country/. 


\section{Despite their popularity, many supports are not available to family caregivers.}

Family caregiving is becoming increasingly common for millions of Americans, and caregivers are becoming more diverse than before, yet support systems and resources have not kept pace. Offering such supports, whether by developing innovative programs or extending existing initiatives, would enable family caregivers to participate more fully in the workforce, bringing immense benefits to the U.S. economy.

These supports can be implemented in several key ways:

- Expanding access to the most highly desired resources, tools, and worker benefits for a greater number of family caregivers is the first step in strengthening support systems. The most helpful resource-flexible work options ${ }^{54}$-was only being used by 11 percent of family caregivers in 2019, pre-COVID-19. Likewise, in the same year, only 6 percent of respondents had used the FMLA, and just 4 percent technology tools ${ }^{55}$ for telework. ${ }^{56}$ Increasing the reach of these tools could have significant benefits for working family caregivers. In addition, improving resources' usefulness to recipients is important. For example, policymakers should require employers to provide employees with a reasonable amount of paid time off.

- Bolstering public programs for family caregivers is the next step. Government programs or credits, one of the highest rated resources for family caregivers, was also among the most commonly used in 2019. This fact underscores the crucial importance of implementing strong public caregiver support programs at national, state, and local levels. These programs provide a lifeline to many across the country. Federal and state governments should provide greater supportive programs and services to assist caregivers by ensuring longterm services and supports (LTSS) programs covering services such as respite care and adult day services. Federal and state governments should also provide tax credits or incentives, and cash allowances, or both, to caregivers and ensure employers to use existing tax incentives, such as flexible spending accounts for dependent care, to provide dependent- or family-care benefits. ${ }^{57}$

\section{- Enabling the widespread adoption} of supportive employer policies is vital in allowing our nation's family caregivers to thrive both at home and in the workplace. Access to flexible workplace policies and employment supports helps family caregivers balance competing demands from their job and family responsibilities. Public and private employers should provide more flexible work options, such as alternative work schedules, flextime, telecommuting, jobsharing, and retiree reemployment programs. Federal, state, and local governments should expand baseline protections under FMLA by covering more employed family caregivers, expanding the definition of family responsibilities, and protecting family caregivers against job discrimination. Additionally, there is significant room for improvement in the areas of paid family leave, paid sick days, and greater flexibility to use sick time for family caregiving responsibilities. Employers also play a role in providing such leave policies to employees. They should offer flexible workplace policies such as the option for employees to use earned sick time to care for a family member. According to 2019 AARP research, only 17 percent of small businesses provided paid time off for family caregiving, but 43 percent said they would like to add paid leave to their offerings. ${ }^{58}$

\section{- Developing and executing a} national caregiving strategy will help governments, employers, and communities identify innovative actions they can take to support family caregivers. In pursuit of this goal, in 2018 the U.S. passed the Recognize, Assist, Include, Support and Engage (RAISE) Family Caregivers Act. This law-and other focused efforts like it—can help spur the development of solutions for better supporting family caregivers, with a focus on areas such as increasing financial security, addressing disparities, providing respite and training options, and identifying workplace policies that help family caregivers remain engaged. 59,60

\footnotetext{
54. These include flexible hours and shifts; job sharing; compressed work schedules; telecommuting; part-time options; and part- to full-time or full-to part-time transitions 55. These include an internet connection, tablets, laptops or other portable technology devices, and videoconferencing platforms.

56. The Economist Intelligence Unit 2019.

57. For more information, please see AARP Policy Book, https://policybook.aarp.org

58. AARP, "Small employers' experience with family caregiving." 2019.

https://www.aarp.org/content/dam/aarp/research/surveys_statistics/econ/2019/small-employers-experiences-family-caregiving.doi.10.26419-2Fres.00307.001.pdf.

59. Richard Eisenberg, "What the New RAISE Family Caregivers Act Will Do." 2018. https://www.nextavenue.org/raise-family-caregivers-act-will-help-family-caregivers/.

60. Hearts for Home Care, "Trump Signs RAISE Family Caregivers Act, Brining Hope to Over 40 million Family Caregivers Nationwide." 2018.

https://heartsforhomecare.bayada.com/trump-signs-raise-family-caregivers-act-bringing-hope-to-over-40-million-family-caregivers-nationwide/.
} 


\section{Final thoughts: Supporting working family caregivers is an investment with a strong return}

Caregiving for an aging relative-once one of the most personal and private matters in family life-is a growing public issue. The costs of caregiving impact both individual workers and employers. When it becomes stressful to juggle caregiving activities with work and other family responsibilities, or if work requirements come into conflict with caregiving tasks, some employed caregivers make changes in their work life-the most drastic one being to leave a job altogether. There is no one-size-fits-all approach or policy to creating a caregivingfriendly workplace. Nevertheless, this report reveals a compelling business case for increasing family caregiver supports and inclusion in the workplace. People age 50-plus are eager to continue working, and they bring a wealth of experience and expertise that vastly benefits companies and other employees, especially younger colleagues. Demographic shifts in the U.S. over the next three decades will increasingly mean that the 50-plus population will take on more family caregiving responsibilities, but this should not be allowed to hinder their ability to remain in and contribute to the workplace.
When 50-plus family caregivers have access to well-supported jobs and incomes, everyone and the whole economy benefits. The effects of caregivers' continued engagement in the workforce will ripple outward, generating more jobs and incomes across regions, demographics, and age groups. Further, while this analysis has focused on the economic impact of supporting working family caregivers age 50-plus, employed family caregivers of all ages will gain from flexible work options, family leave and paid sick days, and a culture of understanding about the caregiving responsibilities that they shoulder.

Employed family caregivers are a much needed source of economic strength amidst a struggling U.S. economy. Their importance will only grow, both nearand long-term-as we work to emerge from the recession wrought by the pandemic, and as the U.S. population continues to age in coming years. 


\section{Appendix 1: Notes on the methodology}

This scenario measures how providing support to family caregivers age 50 -plus would enable them to remain more active participants in the labor force (i.e., what if family caregivers were able to participate in the labor force at the same level as before taking on the role of caregivers) and explores how this would affect the U.S. economy. Specifically, it examines the following four dynamics across full-time workers, part-time workers, and retirees:

\section{Reducing hours worked}

- Those age 50-plus who either reduce their hours or move from full-time to part-time work in order to accommodate family caregiving responsibilities

\section{Taking unpaid leaves of absence}

- Those age 50-plus who take unpaid leaves of absence to attend to family caregiving duties

\section{Passing up a promotion or an opportunity for more pay}

- Those age 50-plus who are forced to turn down opportunities for career advancement or wage growth

\section{Dropping out of the labor force}

- Those age 50-plus who either drop out of the labor force or retire early as a result of family caregiving obligations

\section{Modeling potential attainable impact}

The potential impact of addressing the labor market and wage effects of unpaid family caregiving responsibilities was modeled separately for these four dynamics:

1. The prevalence of family caregivers who cut back on hours or switch to part-time work (across different age and gender cohorts) was estimated using data from the AARP and National Alliance for Caregiving "Caregiving in the U.S. 2020" report. The potential increase to hours worked was calculated by comparing the average number of hours worked by each caregiver population (source: "Caregiving the in U.S. 2020" report) with the average number of hours typically worked by corresponding U.S. full-time/parttime workers (source: U.S. Census).

2. The prevalence of family caregivers who take unpaid leaves of absence (across age and gender cohorts) was estimated using data from "Caregiving in the U.S. 2020" and from the 2019 Economist Intelligence Unit survey. The potential increase to hours worked was estimated using data on the average duration of FMLA leave taken in a year (source: ComPsych's FMLASource, 2015; Abt Associates Inc. "Family and Medical Leave in 2012: Technical Report," 2014).
3. The prevalence of family caregivers who pass up a promotion or an opportunity for more pay (across age and gender cohorts) was estimated using data from "Caregiving in the U.S. 2020" and from the 2019 EIU survey. The potential increase to wages for each cohort was developed using data from the Automatic Data Processing, Inc., (ADP) Workforce Vitality Report 2018 on differences in average wage growth between those able to switch jobs and those who remain in their current positions.

4. The prevalence of family caregivers who drop out of the labor force (across age and gender cohorts) was estimated using data from "Caregiving in the U.S. 2020." This was done separately for those who retire early and those who temporarily give up working. For those age 50-64 who temporarily drop out, the proportion who are likely to return to the labor force after their caregiving obligations was estimated based on the share who report experiencing financial strain while caregiving. The number of extra years this group would have participated in the labor force under our scenario was based on the average duration of a caregiving role, by gender (all figures from "Caregiving in the U.S. 2020"). For all other groups and for retirees, the number of extra years these caregivers said they would have remained in the labor force (if they had access to caregiving supports) was estimated for each age/gender cohort using data from the EIU 2019 survey. 


\section{Forecasting: The number of family caregivers aged 50 and older}

The above prevalence (percent) estimates were all applied to the total number of family caregivers aged 50-plus in any given year, which required the development of forecasts through 2050. To develop these, we used two primary points of reference: (1) the projected size of the 80-plus cohort (those most at risk of care) as a proxy indicator for how the number of adult care recipients may change, ${ }^{61}$ and (2) the projected size of the "prime" age cohort for family caregivers (ages 45-64).

Over the next 30 years, the ratio between these two groups (known as the "caregiver support ratio") will fall substantially, signifying a squeeze in the number of potential people available to care for a swelling older population. At one extreme, this would mean significantly fewer family caregivers per recipient, while at the other extreme a much greater share of the population would need to be engaged in family caregiving. In reality, we are likely to end up somewhere in the middle.

Since future family caregiver dynamics are uncertain, we have developed a broad range of forecasts for this scenario that captures multiple potential paths for the future number of caregivers in the U.S.:

\section{Low-end:}

\section{Conservative growth in caregiving}

- Significantly fewer caregivers per recipient

\section{Core forecast:}

\section{A middle-ground estimate}

- A mix of fewer caregivers per recipient but a greater share of the population engaged in caregiving

\section{High-end:}

\section{Liberal expansion in caregiving}

- A much greater share of the population engaged in caregiving

\section{Forecast assumptions}

For all three forecast paths, we assume that the number of "prime age" family caregivers per 80 -plus person will decline in the future - to differing degreesgiven expected demographic trends. In general, there is a tradeoff between maintaining a reasonable number of family caregivers per recipient and preventing an unsustainable rise in the share of the population who are engaged in caregiving.

For the core forecast, we seek to strike the most even balance between these considerations.

- Under this scenario, the number of prime-age family caregivers per 80-plus person will drop to 1.2 by 2050 (the midpoint between the low-end forecast's 0.8 and the high-end forecast's 1.5).

- The number of 50-plus family caregivers would rise to 47 million by 2050 (from 26 million now).

- About 30 percent of those aged 50-plus would be engaged in family caregiving (from 22 percent now).

For the high-end forecast, we assume the number of prime-age family caregivers per 80-plus person is "sticky" or remains relatively stable, despite population pressures. Therefore, the percentage of those aged 45-64 engaged in caregiving will strongly rise, and this group will continue to provide a similar share of total caregiving.

- Under this scenario, the number of prime-age family caregivers per 80-plus person remains near its 2015 level of 1.5 (as measured in AARP's 2015 "Caregiving in the U.S." study).

- The number of family caregivers among all ages 50-plus would grow to 59 million by 2050 (from 26 million now).

- About 38 percent of those aged 50-plus would be engaged in family caregiving (from 22 percent now).
For the low-end forecast, we assume the age 45-64 population is not able to sustain an increase in the share of people engaged in family caregiving.

- Under this scenario, the number of prime-age family caregivers per 80-plus person will drop to 0.8 (falling proportionally with the decline of the caregiver support ratio).

- The number of 50-plus family caregivers would rise to 34 million by 2050 (from 26 million now).

- The share of 50-plus adults engaged in family caregiving would remain at about 21 percent.

\footnotetext{
61. This group has previously been used as a proxy for potential care recipients in the U.S. in the report by AARP Public Policy Institute "The aging of the Baby Boom and the Growing Care Gap: A Look at Future Declines in the Availability of Family Caregivers" at https://www.aarp.org/content/dam/aarp/research/public_policy_institute/ltc/2013/baby-boom-and-the-growing-care-gap-insight-AARP-ppi-Itc.p.
} 


\section{Scenario: Economic Impact Modeling}

To model impact for this caregiving scenario, the EIU adjusted labor force participation rates, wages and productivity in the REMI model based on an aggregation of these four different effects on family caregivers. Our adjustments were specific to each age and gender cohort. Wages were adjusted uniquely for each category, as described above, and overall productivity was adjusted to ensure GDP growth remained consistent with overall changes in employment.

The model then simulates how these factors interact to impact production across industries and consumption across product types, both today and in future years. The resulting model outputs include impacts on GDP, jobs, wages, and consumer spending as a whole and by industry/product.

This approach models labor supply and productivity to establish a GDP aspiration from providing caregiver supports to working family caregivers. The model does not take into account any other demandside factors that may affect the ability of the economy to absorb additional workers.

\section{Details on the survey methodology}

On behalf of AARP, the EIU conducted a national U.S. survey of 5,000 adults aged 50-plus to better understand their perspectives on how they contribute to the economy and society, with a particular focus on employment and caregiving. The survey was fielded via mixed method (phone/CATI and online) in July to August 2019. Geographically, the survey provided coverage of all 50 states + DC, as well as the Census microregions and the broader national regions. Demographically, the survey reached a balanced sample by age of those aged 50-64 and 65-plus (49 percent/51 percent), by gender ( 50 percent/50 percent), by ethnicity (minimum 10 percent African American, 10 percent Hispanic and 5 percent Asian America) with household income split above and below the national average of $\$ 60 \mathrm{~K}$ (50 percent/50 percent),

This report focuses on the caregiving questions for the entire sample, as well as differences by employment status, age, gender, and income. This is one in a series of reports that will be released in 2019 and 2020 using the data from this survey. 


\section{Appendix 2: Charts and tables}

Figure 1

The potential impact of supporting family caregivers

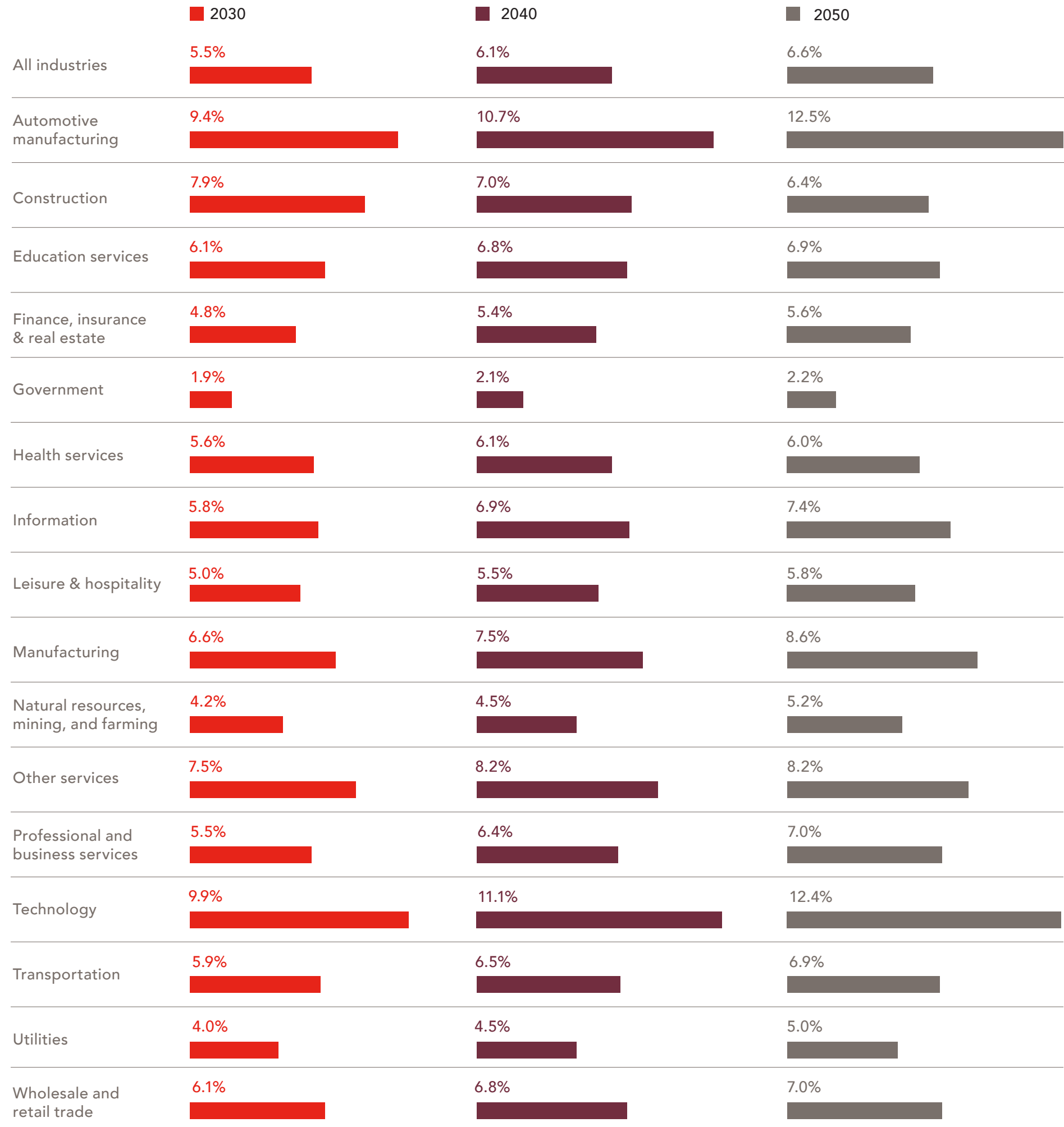

Source: EIU; REMI. 


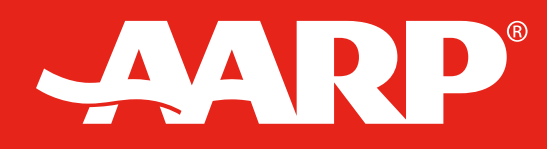

www.aarp.org/longevity

https://doi.org/10.26419/int.00042.006 